\title{
Adhere to REMS Patient Safe Use Conditions
}

National Cancer Institute

\section{Source}

National Cancer Institute. Adhere to REMS Patient Safe Use Conditions. NCI Thesaurus. Code C128526.

The patient must adhere to certain safe use conditions, such as using contraception or following the safe use conditions described in REMS materials. 